\title{
Two cases of congenital anterior urethral diverticulae
}

\author{
Sandeep Ramkrishna Hambarde ${ }^{1}$, Pradnya Suhas Bendre ${ }^{2}$, Ramdas Dagdu Nagargoje ${ }^{1}$, Dinesh \\ Mundada $^{1}$
}

Sri Lanka Journal of Child Health, 2011; 40: 80-81

(Key-words: Anterior urethral diverticulum; diverticulectomy; urethroplasty)

Two cases of congenital anterior urethral diverticulae are presented.

\section{Case 1}

A 4 month old boy presented with swelling of the ventral aspect of the penis during micturation since birth.There was no history of dysuria, poor stream or febrile urinary tract infection (UTI). He had a ritual circumcision at the age of 1 month. Findings on systemic clinical examination were normal. Urinanalysis, blood counts and seum creatinine were within normal limits. Locally, there was swelling on the ventral aspect of the penis with increase in size during micturation. Ultrasonography (USG) showed normal upper tracts. Micturating cystourethrogram (MCUG) showed a large diverticulum making an acute angle with the floor of urethra (Figure 1). Cystoscopy was normal. The diverticulum was excised and urethroplasty was done (Figures 2 \& 3 ). Convalesence was uneventful with no complications during follow up. Postoperative MCUG showed near normal appearance of urethra (Figure 4).

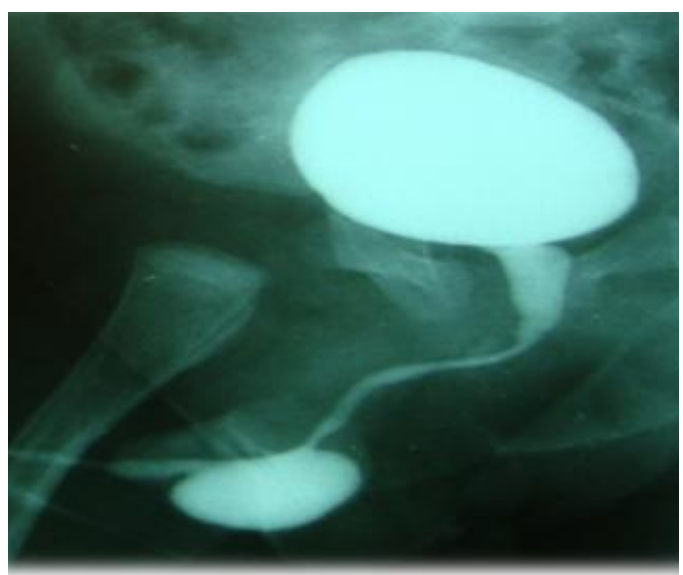

Figure 1: Pre-operative MCUG

\footnotetext{
${ }^{1}$ Senior Resident, ${ }^{2}$ Unit in Charge, Department of Paediatric Surgery, BJWHC, Mumbai, India
}

(Received on 21 October 2010. Accepted on 26 November 2010)

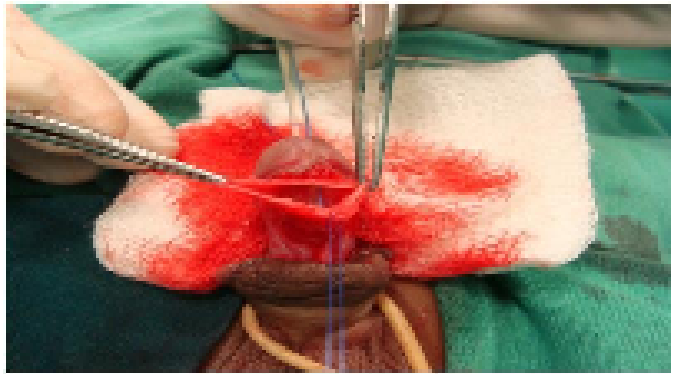

Figure 2: Diverticulectomy being performed

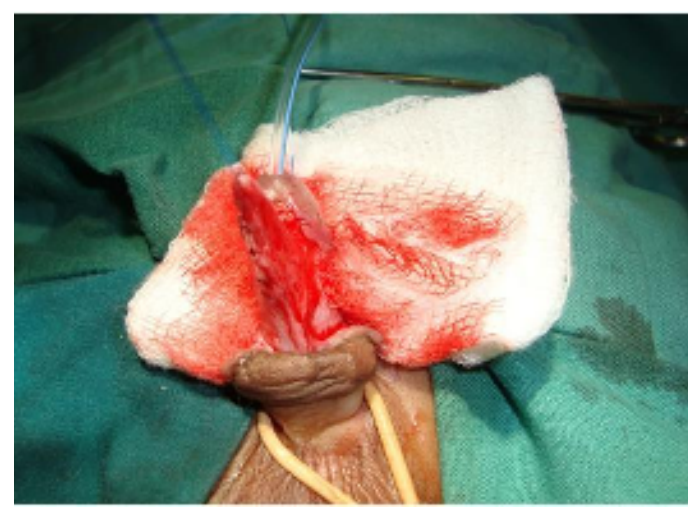

Figure 3: Urethroplasty completed

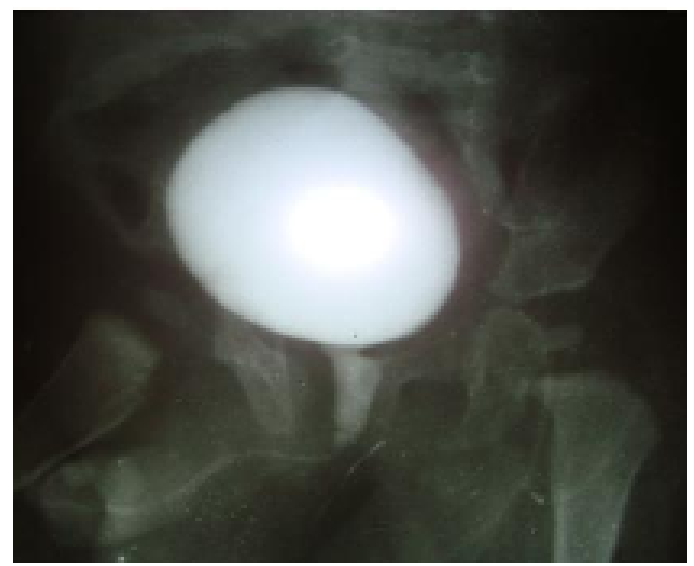

Figure 4: Post-operative MCUG 


\section{Case 2}

A 20 day old neonate presented with swelling of the ventral aspect of the penis and dribbling of urine since birth. There was a history of antenatally diagnosed bilateral hydroureteronephroses. The bladder was palpable. The patient had raised serum creatinine, dyselectrolytaemia, acidosis and UTI. USG showed back pressure changes. MCUG showed a large diverticulum at the penoscrotal junction (Figure 5). Cystoscopy was normal. Open diverticulectomy with urethroplasty was done (Figures 6 \& 7). Post-operative MCUG showed near normal appearance of the urethra and no back pressure changes (Figure 5). The patient had a good urinary stream (Figure 8) and an uneventful 2 month follow up.
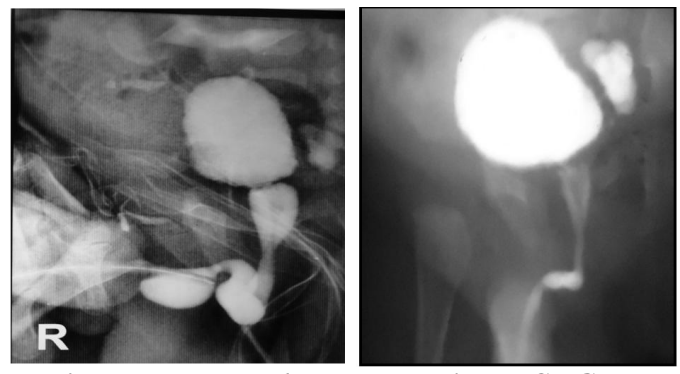

Figure 5: Pre and Post-operative MCUGs

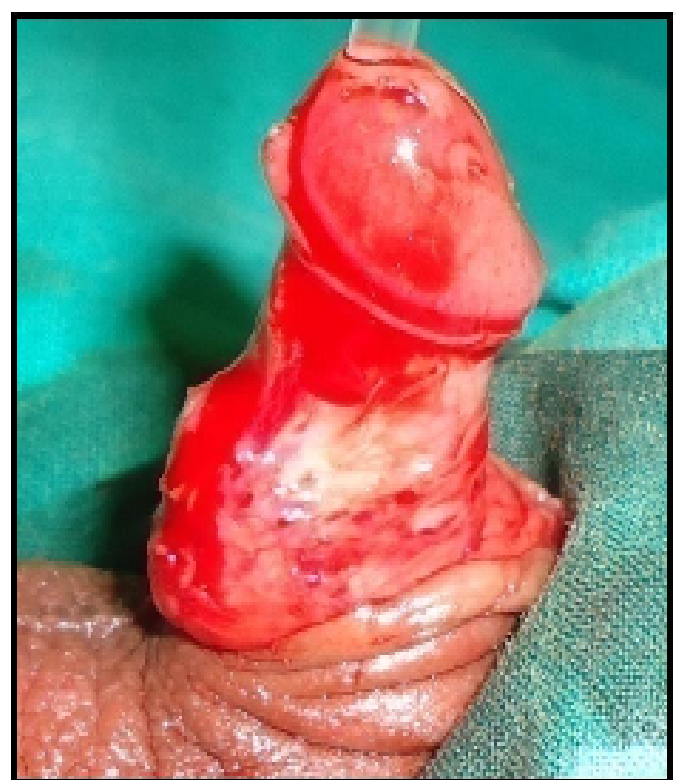

Figure 6: diverticulum exposed

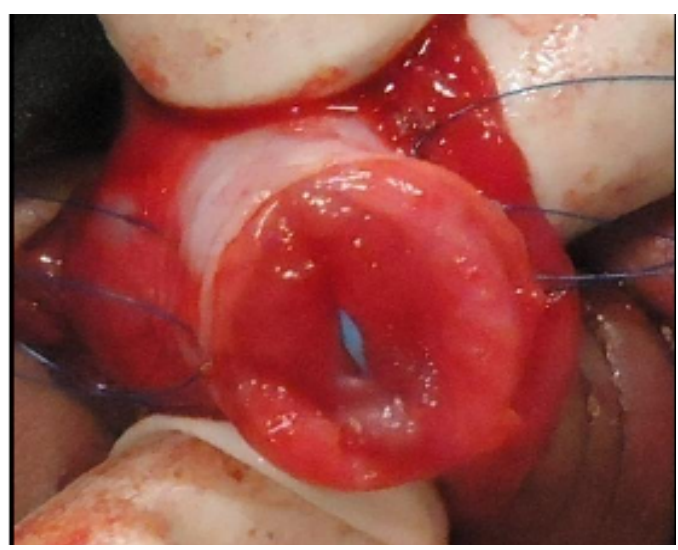

Figure 7: Urethroplasty being performed

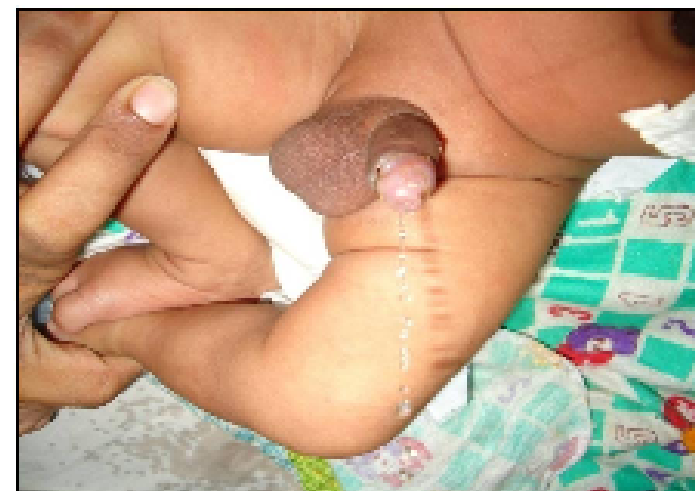

Figure 8: Post-operative urinary stream

\section{Discussion}

Anterior urethral diverticulae with or without valves are rare congenital anomalies causing lower urinary tract obstruction in children ${ }^{1}$. They typically occur where there is a defect in the corpus spongiosum, leaving a thin-walled urethra. This segment of the urethra balloons out during voiding, simulating a mass that is sometimes visible along the ventral wall of the penis. The swelling is fluctuant and urine dribbles from the meatus on compression $^{1}$. The diagnosis is easily established by MCUG. They are best managed by open exicision and urethroplasty ${ }^{1}$.

\section{References:}

1. Rawat J, Khan TR, Singh S, Maletha M, Kureel S. Congenital anterior urethral valves and diverticula: Diagnosis and management in six cases. African Journal of Paediatric Surgery 2009; 6(2): 102-5. 